HARRAN ÜNIVERSITESI MÜHENDISLIK DERGisi

HARRAN UNIVERSITY JOURNAL OF ENGINEERING

e-ISSN: 2528-8733

\section{HARRAN ÜNIVERSITESİ MÜHENDISSLIK DERGİSI}

HARRAN UNIVERSITY JOURNAL of ENGINEERING

e-ISSN: 2528-8733 (ONLINE)

URL: http://dergipark.gov.tr/humder

Farklı Reynolds Sayılarında Panel Etrafındaki Akış Karakteristiklerinin Aerodinamik Kuvvetler Üzerindeki Etkisi

Effects of Flow Characteristics Around the Panel at Different Reynolds Numbers on Aerodynamic Forces

Yazar(lar) (Author(s)): Seher IZOL ${ }^{1}$, Z.Abidin FIRATOĞLU ${ }^{2}$

${ }^{1}$ ORCID ID: 0000-0002-8419-9859

${ }^{2}$ ORCID ID: 0000-0002-2791-6663

Bu makaleye şu şekilde atıfta bulunabilirsiniz (To cite to this article): İzol S., Fıratoğlu Z.A., "Farklı Reynolds Sayılarında Panel Etrafındaki Akış Karakteristiklerinin Aerodinamik Kuvvetler Üzerindeki Etkisi”, Harran Üniversitesi Mühendislik Dergisi, 6(Özel Say1): 49-57, (2021).

Erişim linki (To link to this article): http://dergipark.gov.tr/humder/archive 


Mühendislik Dergisi

\title{
Farklı Reynolds Sayılarında Panel Etrafındaki Akış Karakteristiklerinin Aerodinamik Kuvvetler Üzerindeki Etkisi
}

\author{
Seher İZOL ${ }^{1}$, Zeynel Abidin FIRATOĞLU² \\ ${ }^{1}$ Harran Üniversitesi, Mühendislik Fakültesi, Makine Bölümü, 00000, ŞANLIURFA
}

\begin{abstract}
$\ddot{O ̈ z}$
Makale Bilgisi

Başvuru: 25/01/2021

Yayın: 01/11/2021

Günümüzde alternatif enerji kaynakları arasından öne çıkan alternatif, çevre dostu yenilebilir enerjidir. Konuyla ilgili son yıllarda artan çalışmalara bağlı olarak çok çeşitli yenilebilir enerji uygulaması geliştirilmiştir. Uygulamadaki basitliği nedeniyle ticari alanda öne çıkan yenilebilir enerji uygulaması güneş enerjisidir. Güneş enerjisi uygulamalarında, sistemlerin temel bileşeni tüm atmosferik koşullara maruz güneş enerjisini toplayan helyostat, parabolik veya düz geometrideki toplayıcılardır. Bundan dolayı toplayıcılar bölgenin atmosferik koşulları dikkate alınarak kurulumu bir zorunluluktur. Toplayıcı konstrüksiyonu açısından en kritik parametrelerden biri rüzgâr yüküdür.
\end{abstract}

\begin{tabular}{l} 
Anahtar Kelimeler \\
\hline PV panel \\
Akış karakteristikleri \\
Aerodinamik kuvvetler \\
CFD \\
Rüzgâr yükü
\end{tabular}

Keywords
PVpanel
Flow characteristics
Aerodynamic force
CFD
Wind load

\begin{abstract}
Bu çalışmada 5,15 ve $30 \mathrm{~m} / \mathrm{s}$ serbest akış hızlarında 30 derece eğimli bir fotovoltaik panele gelen rüzgâr yükleri nümerik araştırılmıştır. Panel ön bakış alanının uzunluğu referans uzunluk olmak üzere söz konusu serbest akış hızlarına denk gelen Reynolds sayıları sırasıyla 3.39*10 $1.017 * 10^{5}$ ve $2.03 * 10^{5}$ şeklindedir. Yürütülen araştırma sonucunda Reynolds sayıs $3.36 * 10^{4}$ için sürüklenme katsayısı 1.6025 olduğu saptanmıştır. Reynolds sayısı $1.017 * 10^{5}$ iken sürüklenme katsayısı \% 17.8 oranında dramatik bir şekilde düşmektedir.
\end{abstract}

\section{Effects of Flow Characteristics Around the Panel at Different Reynolds Numbers on Aerodynamic Forces}

\begin{abstract}
Today, the alternative that stands out among alternative energy sources is environmentally friendly renewable energy. A wide variety of renewable energy applications have been developed depending on the increasing studies on the subject in recent years. The renewable energy application that stands out in the commercial area due to its simplicity in application is solar energy. In solar energy applications, the basic component of the systems is the heliostat, parabolic or flat geometry collectors, which collect solar energy exposed to all atmospheric conditions. Therefore, it is a necessity to set up collectors taking into account the atmospheric conditions of the region. One of the most critical parameters in terms of collector construction is the wind load.

In this study, wind loads on a photovoltaic panel inclined at 30 degrees at 5,15 and $30 \mathrm{~m} / \mathrm{s}$ free flow velocities were numerically investigated. With the length of the panel frontal area being as the reference length, the Reynolds numbers corresponding to these free flow velocities are $3.39 * 10^{4}, 1.017 * 10^{5}$ and $2.03 * 10^{5}$, respectively. As a result of the research, the drag coefficient for the Reynolds number $3.36^{*} 10^{4}$ was determined to be 1.6025 . While the Reynolds number is $1.017 * 10^{5}$, the drag coefficient dropped dramatically by $17.8 \%$.
\end{abstract}

\section{GÍRIŞ (INTRODUCTION)}

Günümüzde gerek termal ve gerekse fotovoltaik uygulamalarda çoğunlukla düz toplayıc1lar kullanılmaktadır. Fotovoltaik paneller veya diğer düz toplayıcılar işletme sırasında yağmur, kar, rüzgâr vb. tüm atmosferik koşullara direkt maruzdur. Bu koşullar arasından sistem konstrüksiyonu için en kritik

\footnotetext{
*İletişim yazarı, e-mail: seherizol@hotmail.com

Bu çalışma, 05-06 Kasım 2020 tarihlerinde gerçekleştirilen GAPYENEV Uluslararası Yenilenebilir Enerji ve Enerji Verimliliği Kongresi’nde sözlü bildiri olarak sunulmuștur.
} 
parametre rüzgâr yüküdür. Rüzgâr, etraftaki coğrafi veya yapay yapılara bağlı lokal olarak en çok değişkenlik gösteren bileşendir. Bundan dolayı konu ile ilgili yürütülmüş birçok çalışma bulunmaktadır. Bu çalışmalarda çoğunlukla farklı akış alanları için sistem rüzgâr yükünü tespit etmeye yöneliktir. Panel etrafındaki akış karakteristiklerinin panele gelen aerodinamik kuvvetler ile ilişkisini inceleyen çalışma ise yok denecek kadar azdır. Bundan dolayı sistem rüzgâr yükünü azaltmaya yönelik pasif veya aktif yöntem ve araçlar geliştirmeye yönelik yürütülecek çalışmalar için literatürde yeterince veri bulunmamaktadır.

Geometrik açıdan bir güneş panelinin etrafındaki akış karakteristiğini dramatik olarak değiştiren iki parametre; rüzgâr atak açısı ve panel eğim açısıdır. Söz konusu iki büyüklüğün opti mal koşulları her bölgeye göre değişiklik gösterdiğinden konu ile ilgili literatürde yürütülmüş birçok çalışma bulunmaktadır. Abiola-Ogedengbe ve ark. (2015), 24 panelden meydana gelen bir PV panel modülünün üst ve altındaki basınç alanlarını dört farklı rüzgâr yönü için deneysel olarak ölçmüşlerdir. Ölçümlerde $0^{0}$ ve $180^{\circ}$ rüzgâr açılarında basınç dağılımının simetrik olduğunu diğer yönler için ise asimetrik olduğunu saptamışlardır [1]. Shademan ve ark. (2014), CFD simülasyonları kullanarak PV panel modülleri üzerine gelen rüzgâr yükünü araştırmışlardır. Çalışmalarını çeşitli panel konfigürasyonları ve farklı rüzgâr atak açıları çerçevesinde yürütmüşlerdir. Bağımsız sistemlerdeki panellerde maksimum rüzgâr yükünün $0^{0}$ ve $180^{\circ}$ yönlerde olduğunu tespit etmişlerdir. Araştırma sonucunda paneller arası boşluk, zemin boşluğu ve yükü, rüzgâr yönünün rüzgâr yükünü belirleyen temel parametreler olduğunu saptamışlardır [2]. Velicu ve ark. (2010), rüzgâr tünelinde PV modülünün üzerindeki etkileri belirlemek için deneysel olarak araştırmışlardır. PV panel üzerindeki sürüklenme ve kaldırma kuvvetlerini kuvvet transdüserlerini kullanarak ölçmüşlerdir ve sonuç olarak, panel eğim açısı $0^{0}$ den $90^{\circ}$ ye çıktığında rüzgâr arttıkça kuvvet katsayılarının da arttığını gözlemlemişlerdir [3]. Meroney ve Neff (2010), farklı kolektör destek sistemlerindeki sürtünme, kaldırma ve devrilme momentlerini tahmin etmek için güneş fotovoltaik kolektörlerde rüzgâr yüklerinin sayısal hesaplamalarını kullanarak nümerik ve deneysel olarak araştırmışlardır. Elde ettikleri sayısal sonuçları rüzgâr tüneli deneyleri sırasında elde edilen doğrudan kuvvet ölçüm testleri ile karşılaştırmışlardır. Yürüttükleri çalışmada RNG ve k-omega türbülans modellerinin ölçüm sonuçları örtüşürken k-epsilon türbülans için aynı durumun söz konusu olmadığını saptamışlardır [4]. Jubayer ve Hangan (2016), kararlı giriş koşullarına sahip kararsız bir çözücü kullanan 3D Reynolds-Ortalamalı Navier-Stokes (RANS) simülasyonları, rüzgâr yükünü ve akış alanını, üzerine monte edilmiş 25 paneli 30 derece eğim açısı ile yere monte edilmiş bağımsız bir fotovoltaik (PV) sistemi etrafındaki akış yapısını nümerik araştırmışlardır. Bu nümerik araştırma sonucunda, detaylı yüzey basıncı dağılımlarını ve güneş paneline gelen aerodinamik kuvvetleri hesaplamışlardır [5]. Zemler ve ark. (2013), parabolik biçimli güneş kolektörleri üzerindeki rüzgâr etkilerini nümerik incelemişlerdir. Bu inceleme sonucunda parabolik ve oryantasyonların farklı diyagram boyutları dikkatte alınarak ve uygulanan kuvvetlerin düştüğü saptamışlardır [6]. Harstveit (1996), ani rüzgâr faktörlerinin ve türbülans yoğunluğunun tam ölçekli ölçümleri ve engebeli arazideki ilişkilerini incelemek için nümerik bir çalışma yapmıştır. Yaptığı araştırmada engebeli arazilerde rüzgâr yapısının konuma bağlı dramatik değişimler gösterdiği saptamıştır [7]. Toja-Silva ve ark. (2015), çatıya monte edilmiş güneş panellerinin bina çatıları üzerindeki rüzgâr akımı üzerindeki etkilerini nümerik olarak araştırmışlardır. Çalışmalarında CFD simülasyonlarını OpenFoam yazılımı ile gerçekleştirmişlerdir. Simülasyonlarını izole edilmiş bir bina için yürütülmüş olan iki deneysel ölçüm verisi ile doğrulamışlardır. Çalışmalarını $10^{\circ}$ ve $30^{\circ}$ şeklinde iki panel eğimi çerçevesinde yürütmüşlerdir. Yaptıkları araştırmada tam ölçekli bina sonuçları, küçük ölçekli bir modelle karşılaştırmış ve ölçeklendirme sorunlarını bildirmişlerdir. Ek olarak, sonuçlarını meshten bağımsız olarak yürütmüşlerdir [8]. Banks (2013), geniş, alçak ve dikdörtgen düz bir çatıya yerleştirilmiş eğik PV panele gelen rüzgâr yüklerini, atmosferik sınır tabaka rüzgâr tünelinde ölçmüştür. Yaptığı ölçümlerde bina geometrisi ve panelin binaya göre konumlandırılmasıyla panel etrafındaki akış alanın büyük oranda değiştirilebileceğini saptamıştır [9]. Radu ve ark. (1986), rüzgâr tüneli deneyleri ile panellere gelen rüzgâr yüklerini deneysel ve nümerik olarak araştırmışlardır. Çalışmalarında 5 katlı bir binanın çatısına yerleştirilmiş panel konfigürasyonunu referans almışlardır. Yaptıkları deneylerde ön sıradaki panellerin arka sıradaki panellere nazaran daha büyük yüklere maruz kaldıklarını tespit etmişlerdir. $\mathrm{Bu}$ tespit sırasında -1.4 ve +1.25 arasında değişen kuvvet katsayılarında maksimum varyasyonların gerçekleştiğini gözlemlemişlerdir ve sonraki çalışmalar bunların destek yapıları olan paneller üzerindeki kaldırma kuvvetlerini de araştırmışlardır [10]. Wood ve ark. (2001), rüzgâr tüneli ile ölçekli bir bina modelinin düz çatıları üzerine PV modülleri monte edip, oluşacak etkileri deneysel 
araştırmışlardır. Yaptıkları deneysel çalışmada panel üzerinde etkili olan basınç katsayısı tepe değerlerinin -0.2 ile +0.2 arasında dalgalanmaların olduğunu gözlemlemişlerdir. Vardıkları bir diğer sonuç ise iki panel dizisi arasındaki mesafe, çatı ve panel yüksekliği, paneller arasındaki yanal boşlukların akış alanı üzerinde dramatik değişimlere sebep olduğudur [11]. İzol (2019), yaptığı çalışmada PV panelin yüzeye farklı montaj şekillerinin ve farklı atak açılarında panel etrafındaki akış karakteristiklerinin aerodinamik kuvvetler ile ilişkisini deneysel ve nümerik araştırmıştır. Yaptığı araştırmada maksimum sürüklenme katsayısının sıfır atak açısında meydana geldiğini ve bu atak açısında kaldırma kuvveti minimum olduğunu tespit etmiştir. Kaldırma katsayısı ise 75 derecelik atak açısında maksimum olduğu ve kaldırma katsayısı için kritik bir noktanın 30 derecelik atak açısı olduğu vardığı diğer bir sonuçtur. Söz konusu noktadan önce kaldırma kuvvetinin yönü, yerçekimi ivmesinin yönü ile aynı iken bu noktadan sonra kaldırma kuvveti yön değiştirmektedir [12]. Fıratoğlu ve ark (2020), yaptıkları çalışmada $30^{\circ}$ eğimli endüstriyel bir panelin rüzgâr yükünü CFD simülasyonlarıyla araştırmışlardır. Simülasyonlarını 5 ve 10 $\mathrm{m} / \mathrm{s}$ serbest akış hızında gerçekleştirmişlerdir. Yürütülen simülasyonlar sonucunda her iki akış hızı için panel etrafındaki akış alanı tanımlanmış ve tanımlanan bu akış alanından aerodinamik kuvvet ve momentleri hesaplamışlardır. Yürüttükleri simülasyonlar sonucunda, sürüklenme ve kaldırma katsayılarını birlikte değerlendirdiklerinde, $30^{\circ}$ eğimli ve $0^{0}$ rüzgâr atak açısında seçilen PV panele için kaldırma kuvveti sürükleme kuvvetinden yaklaşık olarak \%73 daha büyük olduğunu saptamışlardır [13].

Güneş enerjisi uygulamalarında büyük çoğunlukla sistemlerde en büyük alan ve hacim işgal eden bileşenler, toplayıcılardır. Dolayısıyla toplayıcıların rüzgâr yükünün belirlenip kurulum açısından optimal tasarım parametrelerinin belirlenmesi kritik bir öneme sahiptir. Yukarıda konu ile ilgili sunulan başlica literatür bilgilerinden görüleceği üzere bir sistemin rüzgâr yükü, panellerin eğim açısı, rüzgar atak açısı panellerin yerden yüksekliği, panellerin birbirine göre konumu şeklindeki başlıca parametrelere bağlı olarak dramatik sapmalar görülmektedir. Bu çalışmada seçilen endüstriyel bir panelin etrafındaki akış alanının aerodinamik kuvvetler ile ilişkisi CFD simülasyonları ile araştırılmıştır.

\section{MATERYAL VE METOD (MATERIAL AND METHOD)}

Şekil 1'de bir akış alanındaki katı bir modele etki eden sürüklenme $\left(F_{D}\right)$ kaldırma $\left(F_{L}\right)$, yanal $\left(F_{Y}\right)$ şeklindeki aerodinamik kuvvetler ve yunuslama $\left(\mathrm{M}_{\mathrm{YU}}\right)$, sapma $\left(\mathrm{M}_{\mathrm{S}}\right)$, yalpalama $\left(\mathrm{M}_{\mathrm{YA}}\right)$ şeklindeki aerodinamik momentler gösterilmiştir. Bu çalışmada değerlendirmeler, söz konusu aerodinamik kuvvet ve momentler çerçevesinde yapılmıştır. PV panel, akış alanına sıfır atak açısı ve 30 derece eğimli şekilde yerleştirilmiştir. İlk etapta seçilen endüstriyel panelin katı modeli hazırlanmış hazırlanan katı model Şekil 1'de görülebilir.

Tablo 1. Farklı mesh sayılarında yürütülen simülasyonlarda panel yüzeyinin ortalama basınç katsayısl.

\begin{tabular}{|c|c|c|}
\hline $\mathbf{U}_{\infty}$ & Mesh Sayısı & $\mathbf{C}_{\mathbf{P}}$ \\
\hline \multirow{3}{*}{ हैं } & 6825626 & -0.70030743 \\
\cline { 2 - 3 } & 8190800 & -0.707310502 \\
\cline { 2 - 3 } & 5688021 & -0.710383609 \\
\hline
\end{tabular}




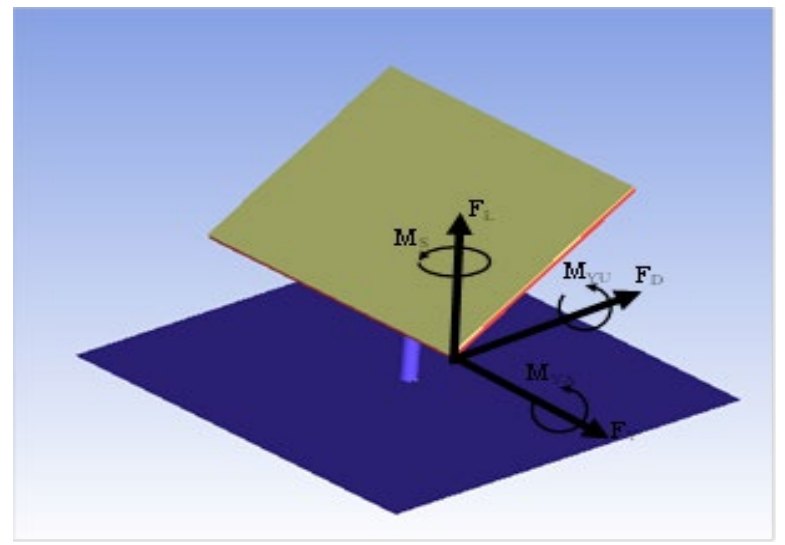

Şekil 1. Aerodinamik kuvvet ve momentlerin şekil üzerinde gösterimi.

Mesh Yapısı: İlk etapta simülasyonların güvenilirliğini test etmek ve meshten bağımsız çözüm elde etmek amaciyla 6825626, 8190800, 5688021 olmak üzere üç farklı mesh sıklığında simülasyonlar yürütülmüştür. Gerçekleştirilen ilk simülasyonlarda mesh sayısının sonuca etkisinin ihmal edilebilir derecede olduğu saptanmıştır. Örneğin farklı mesh sıklığının ortalama basınç katsayısındaki sapma oranı \% 3'ün altında kalmıştır. Bu sonuç yürütülecek simülasyonun meshten bağımsız olduğunun bir göstergesidir. $5 \mathrm{~m} / \mathrm{s}$ serbest akış hızında yürütülen simülasyonda yüzey boyunca y plus katsayısının dağılımı Şekil 2'de gösterilmiştir. Şekilden görüleceği üzere tüm yüzeylerde y plus katsayısı 10'un altında kalmaktadır. $\mathrm{Bu}$ sonuç yapılan mesh tasarımının seçilen türbülans modeline uygun olduğunu göstermektedir.

Nihai simülasyonlar 5688021 mesh sıklığında gerçekleştirilmiştir. Söz konusu mesh yapısı Şekil 3'te gösterilmiştir. Şekilden görüleceği üzere tüm akış alanı için mesh yapısı olarak hexamesh tercih edilmiştir. Farklı mesh yapılarında yürütülen simülasyonlar sonucunda ortalama basınç katsayısının dağılımı Tablo 1'de verilmiştir. Tablodan görüleceği üzere sapma \%2'nin altındadır. Dolaysıyla simülasyon meshten bağımsızdır.

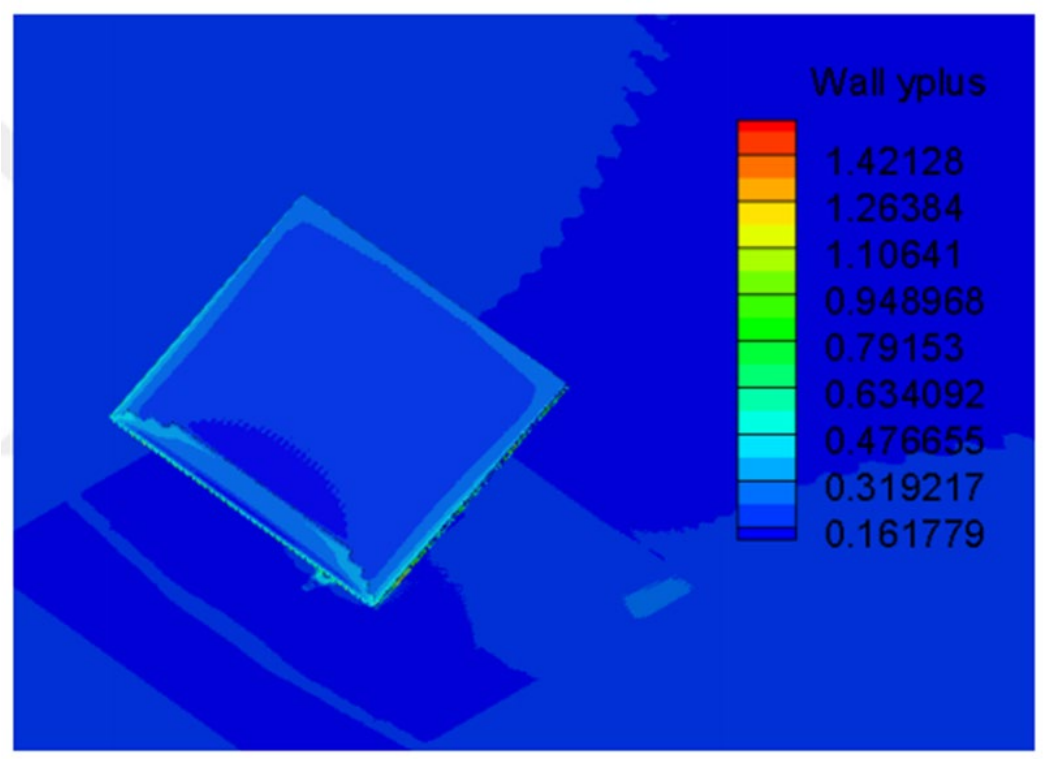

Şekil $1.5 \mathrm{~m} / \mathrm{s}$ serbest akış hızında yüzeylerdeki y+ katsayısının dăğlımı. 


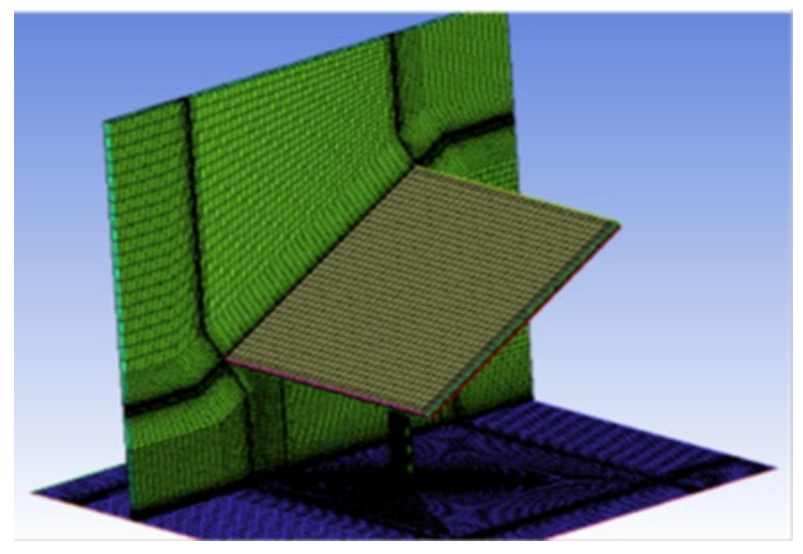

Şekil 2. Akış alanının mesh yapısı

Nümerik analizler için İcemCFD programında tasarlanan $2.375 \times 1 \times 0.6 \mathrm{~m}^{3}$ boyutlarındaki akış alanına, deneylere uygun panel, yatay yüzeye dikey konumda yerleştirilmiştir. Tasarlanan akış alanı ve sınırları Şekil 4'te gösterilmiştir. Giriş, panel merkezinde ve panel üsten bakış alanının yatay mesafesinden 3 kat önde iken çıkış, 7 kat geridedir.

Girişte v, w hız bileşenleri sıfır, u hızı ise deneylerde panelin konulacağı noktada yapılan hız ölçümlerinde tespit edilen sınır tabakaya uygun olarak tam gelişmiş türbülans akış hız profili şeklinde alınmıştır. $\mathrm{Bu}$ hız profilin tespiti, giriş ile aynı mesh yapısına sahip düz levha üzerinde yapılan nümerik analizler ile tespit edilmiştir. Çıkış sınır şartı olarak ise sıfır gradyan $\left(\frac{\partial}{\partial x 1}=0\right)$ alınmıştır.

Akış alanında tüm katı yüzeyler (panel, çerçeve zemin, panelin yüzeye montaj bileşeni duvar (kaymama $\left.\left(\frac{\partial \cup i}{\partial x i}=0\right)\right)$ sınır şartı alınmıştır. Bu yüzey iki parça şeklinde tasarlanmıştır.

Akış alının üst ve yan yüzeyleri simetri sınır şartı alınmıştır. Simetri sınır şartında sınırda herhangi bir akış yoktur. Bu yüzeyde yüzeye dik herhangi bir bileşenin gradyanı sıfırdır. Dolayısıyla yüzeylerin akış alanına herhangi bir etkisi söz konusu değildir.

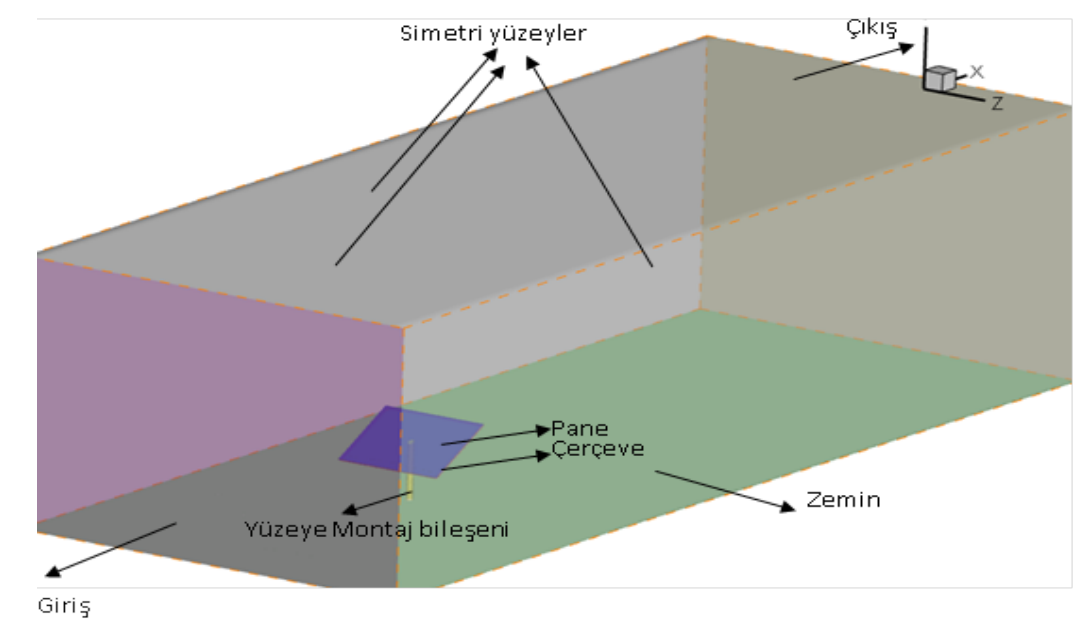

Şekil 3. Tasarımı gerçekleşen panelin akış alanı ve sınır şartlarının şematik görünümü.

Türbülans Modeli: Ters basınç gradyanının olduğu sınır tabaka akışlarında en iyi performansı k- $\omega$ türbülans modeli gösterir $[14,15]$. Literatürde $\mathrm{k}-\omega$ modelinin üç versiyonu vardır; (i) orijinal k- $\omega$ model, (ii) k- $\omega$, BSL (baseline) model ve (iii) k- $\omega$ SST (shear-stress transport) model. Wilcox'un orijinal modelinden türetilen son iki model, [14] ters basınç gradyanına maruz akışlar için yüksek hassasiyettedir. 
Menter [15], (i) klasik k- $\varepsilon$ modeli, (ii) orijinal k- $\omega$, (ii) k- $\omega$, BSL, ve k- $\omega$, SST modelleri arasında çok geniş bir alanda karşılaştırma yapmıştır. Karşılaştırma için seçtiği geriye adım akışı ve maksimuma yakın hücum açısındaki Naca 4412 kanat profili üzerinden akış uygulamalarında ters basınç gradyanları son derece yüksektir. Yapılan bu karşılaştırmalarda k- $\omega$, SST modeli en doğru sonuçları vermiştir. Yüzey üzerine monte edilmiş panel önündeki son derece yüksek ters basınç gradyanları olduğundan, türbülans modeli olarak k- $\omega$, SST seçilmiştir.

\section{BULGULAR VE TARTIŞMA (RESULTS AND DISCUSSION)}

$5 \mathrm{~m} / \mathrm{s}$ serbest akış hızında ve sıfır atak açısında panel ön ve arka yüzeyi boyunca basınç katsayısının dağılımı Şekil 5'te gösterildiği üzere panel ön yüzeyinde akışa maruz ilk kısımda basınç katsayısının değeri 1 olmaktadır. Daha sonra basınç katsayısı kademeli olarak düşmekte ve uç bölgelerde sıfırın altında değerlere ulaşmaktadır. Yine şekilde görüleceği üzere panel akışa göre ön uç bölgesi hariç diğer uç bölgelerde basınç katsayısı sıfırın üstünde değerler almaktadır. Panel ön yüzeyinde akışa göre ön yüzeyin ucunda basınç katsayısı değeri 1 iken panel ön boyunca hemen dramatik olarak yaklaşı \%33 düşmektedir. Söz konusu dramatik düşüş panel boyunca devam etmektedir. Panelin arka yüzeyinde akışa göre ön uç bölgesinin küçük bir bölgesinde basınç katsayısı maksimum 0.194 ile sıfırın üstündedir. Geriye kalan panel arka yüzeyinde ise basınç katsayısı sıfırın altında olmaktadır. Gerek panel ön ve gerekse panel arka yüzeyinde basınç katsayısı minimum-2.474 değerini almaktadır. Bu değere panel arka yüzeyinde panel arka ucuna yakın $Z=0$ eksenine göre simetrik iki bölgede ulaşılmaktadır. Dolayısıyla panel yüzeyine dik panelden dışarıya doğru en büyük basınç kuvvetleri bu bölgede meydana gelmektedir. Gerek panel ön yüzeyinde ve gerekse panel arka yüzeyinde ön uçlar hariç diğer uçlarda basınç katsayısı sıfırdan daha küçüktür. Ancak arka yüzeydeki uç bölgelerdeki negatif basınç katsayısı değeri ön yüzeyin yaklaşık üç katıdır.
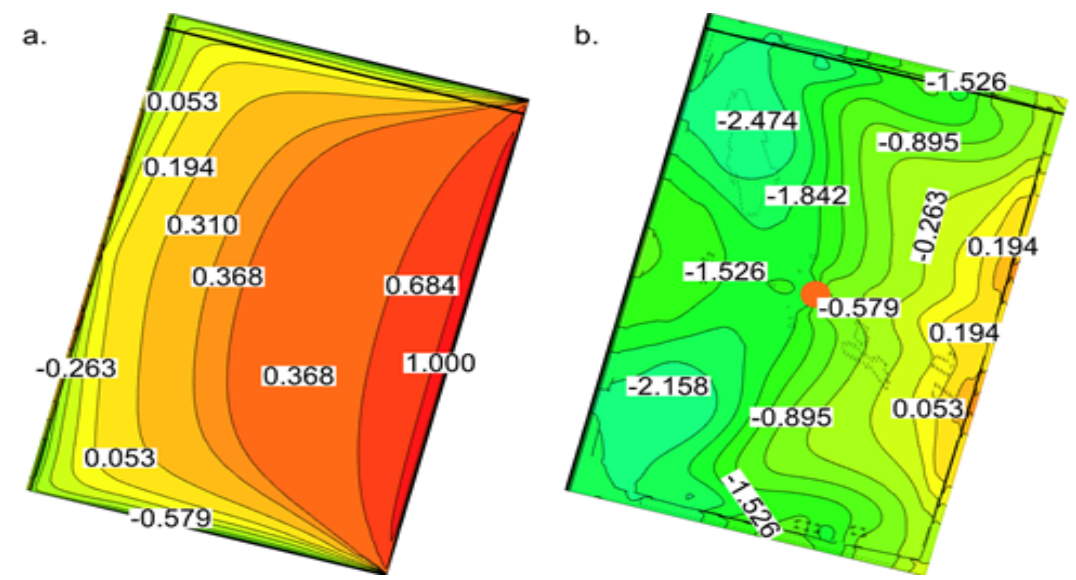

Şekil 5. $R e=3.39 * 10^{4}$ sayılarında ön ile arka yüzeyinde basınç katsayısının $\left(C_{P}\right)$ dă̆ıllımı.

$15 \mathrm{~m} / \mathrm{s}$ serbest akış hızında ve sıfır atak açısında panel ön ve arka yüzeyi boyunca basınç katsayısının dağılımı Şekil 6'da gösterildiği üzere panel ön yüzeyinde akışa maruz ilk kısımda basınç katsayısının değeri 1 olmaktadır. Daha sonra basınç katsayısı kademeli olarak düşmekte ve uç bölgelerde sıfır değerlerine ulaşmaktadır. Yine şekilden görüleceği üzere panel akışa göre ön uç bölgesi hariç diğer uç bölgelerde basınç katsayısı sıfırın üstünde değerler almaktadır. Panel ön yüzeyinde akışa göre ön yüzeyin ucunda basınç katsayısı değeri 1 iken panel ön boyunca hemen dramatik olarak yaklaşı \%37.5 düşmektedir. Söz konusu dramatik düşüş panel boyunca devam etmektedir. Panel ön yüzeyinde basınç katsayısının 1 olduğu bölge $\mathrm{U}_{\infty}=5 \mathrm{~m} / \mathrm{s}$ serbest akıştaki simülasyona nazaran yaklaşık iki katı daha fazladır. Panelin arka yüzeyinde akışa göre ön uç bölgesinde basınç katsayısı maksimum sıfır olmaktadır. Geriye kalan panel arka yüzeyinde ise basınç katsayısında dramatik değişimler söz konusudur. Gerek panel ön ve gerekse panel ön yüzeyinde basınç katsayısı minimum -4.5 değerini almaktadır. Bu değere, panel arka yüzeyinde panel arka ucuna yakın $\mathrm{Z}=0$ eksenine göre simetrik iki bölgede ulaşılmaktadır. Dolayısıyla panel yüzeyine dik panelden dışarıya doğru en büyük basınç kuvvetleri bu bölgede meydana gelmektedir. 
Gerek panel ön yüzeyinde ve gerekse panel arka yüzeyinde ön uçlar hariç diğer uçlarda basınç katsayısı sıfırdan daha küçüktür. Ancak arka yüzeydeki uç bölgelerdeki negatif basınç katsayısı değeri ön yüzeyin yaklaşık dört katıdır.
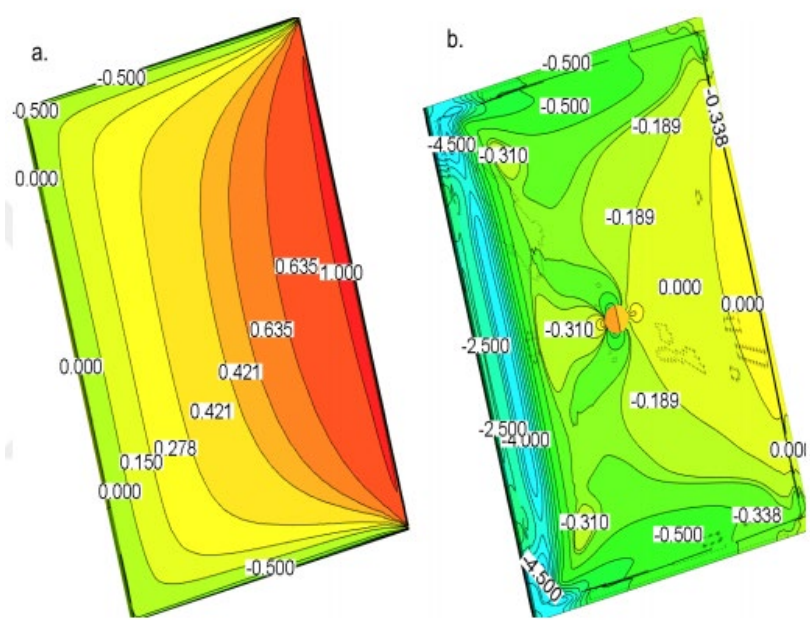

Şekil 4. $R e=1.017 * 10^{5}$ sayılarında ön ile arka yüzeyinde basınç katsayısının $\left(C_{P}\right)$ dağıllımı.

$30 \mathrm{~m} / \mathrm{s}$ serbest akış hızında ve sıfır atak açısında panel ön ve arka yüzeyi boyunca basınç katsayısının dağılımı Şekil 7'de gösterilmiştir. Şekilde görüleceği üzere panel ön yüzeyinde akışa maruz ilk kısımda basınç katsayısının değeri 0.805 olmaktadır. Daha sonra basınç katsayısı kademeli olarak düşmekte ve uç bölgelerde sıfırın altında değerlere ulaşmaktadır. Yine şekilden görüleceği üzere panel akışa göre ön uç bölgesi hariç diğer uç bölgelerde basınç katsayısı sıfırın üstünde değerler almaktadır. Panel ön yüzeyinde akışa göre ön yüzeyin ucunda basınç katsayısı değeri 0.805 iken panel ön boyunca ilk etapta $\% 15$, daha sonra artan oranlarda düşmektedir. Panel ön yüzeyinde basınç katsayısının 1 olduğu bölge $U_{\infty}=5$ ve 15 $\mathrm{m} / \mathrm{s}$ serbest akıştaki simülasyonlara basınç katsayısındaki düşüş daha düşük kademelerde gerçekleşmektedir. Panelin arka yüzeyinde akışa göre ön uç bölgesinde basınç katsayısı belli bir bölgede sıfırın üstünde olmaktadır. Geriye kalan panel arka yüzeyinde ise basınç katsayısında dramatik değişimler söz konusudur. Gerek panel ön ve gerekse panel arka yüzeyinde basınç katsayısı minimum -4.5 değerini almaktadır. Bu değere panel arka yüzeyinde panel arka ucuna yakın $\mathrm{Z}=0$ eksenine göre simetrik iki bölgede ulaşılmaktadır. Dolayısıyla panel yüzeyine dik panelden dışarıya doğru en büyük basınç kuvvetleri bu bölgede meydana gelmektedir. Gerek panel ön yüzeyinde ve gerekse panel arka yüzeyinde ön uçlar hariç diğer uçlarda basınç katsayısı ya sıfırdan daha küçük ya da büyüktür.
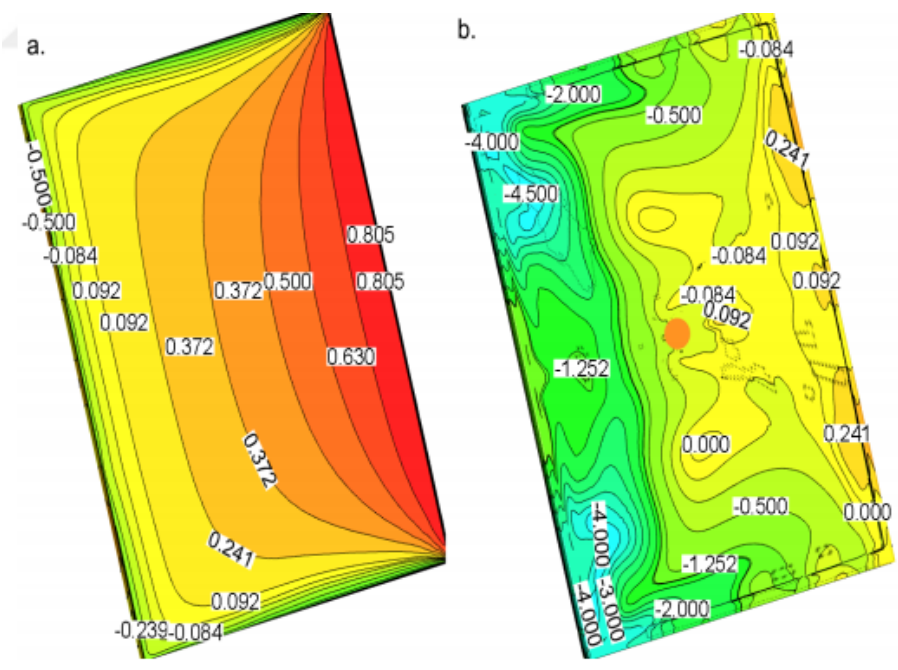

Şekil 5. Re=2.03*10 sayılarında ön ile arka yüzeyinde basınç katsayısının $\left(C_{P}\right)$ dăğllımı. 


\section{SONUÇ (CONCLUSION)}

$3.39 * 10^{4}, 1.017 * 10^{5}$ ve $2.03 * 10^{5}$ Reynolds $(\mathrm{Re})$ sayıları ile sırasıyla yürütülen CFD simülasyonları sonucunda panel için hesaplanan sürüklenme $\left(\mathrm{C}_{\mathrm{D}}\right)$, kaldırma $\left(\mathrm{C}_{\mathrm{L}}\right)$ katsayıları ve yunuslama $\left(\mathrm{M}_{\mathrm{YU}}\right)$, sapma $\left(\mathrm{M}_{\mathrm{S}}\right)$ ile yalpalama (M $\left.\mathrm{M}_{\mathrm{YA}}\right)$ moment katsayıları Tablo 2'de verilmiştir. Sürüklenme ve kaldırma katsayılarının Reynolds sayılarına göre değişimi de Şekil 8'de gösterilmiştir. Tablo ve şekilden anlaşılacağ 1 üzere Reynolds sayıs $3.36^{*} 10^{4}$ için sürüklenme katsayıs1 1.6025 'tir. Reynolds sayıs1 $1.017 * 10^{5}$ iken sürüklenme katsayısı $\% 17.8$ oranında dramatik bir şekilde düşmektedir. Serbest akış hızı $15 \mathrm{~m} / \mathrm{s}$ olduğunda ise $\mathrm{U}_{\infty}=10 \mathrm{~m} / \mathrm{s}$ akış hızına göre sürüklenme katsayı $\% 5.148$ şeklinde daha düşük bir oranda düşmekte ve 1.2492 değerini almaktadır.

$\mathrm{U}_{\infty}=15 \mathrm{~m} / \mathrm{s}$ akış hızı iki katına çıkarıldığında ise sürüklenme katsayısı \%15.4 oranında artmaktadır. Dolayısıyla $\mathrm{Re}=6.78 * 10^{4}-2.03 * 10^{5}$ aralığında kritik bir nokta söz konusudur. Ara akış hızları için simülasyonlar yürütülmediğinden kritik nokta tam olarak tespit edilememiştir. Bu sonuç literatürdeki benzer çalışmaların sonuçlarıyla örtüşmektedir. Gerek Tablo 2 ve gerekse Şekil 8'den görüleceği üzere benzer kritik durum kaldırma katsayısında da görülmektedir. Kaldırma katsayısının eksi değerler alması akışkanın paneli aşağıya doğru ittiğini göstermektedir.

Tablo 2. Farklı Reynolds sayılarında yürütülen simülasyonlar sonucunda hesaplanan aerodinamik büyüklükler.

\begin{tabular}{|l|l|l|l|l|l|}
\hline$R e$ & $C_{D}$ & $C_{L}$ & $M_{Y U}$ & $M_{S}$ & $M_{Y A}$ \\
\hline $\mathbf{3 . 3 9} * 10^{4}$ & $\mathbf{1 . 6 0 2 5}$ & $-\mathbf{2 . 7 7 7 3}$ & $\mathbf{1 . 0 1 4 3 e - 0 1}$ & $\mathbf{4 . 3 6 2 4 \mathrm { e } - 0 4}$ & $\mathbf{8 . 3 8 0 0 \mathrm { e } - 0 4}$ \\
& & & & & \\
\hline $\mathbf{1 . 0 1 7} * \mathbf{1 0}$ & 1.2492 & -2.1778 & $1.1926 \mathrm{e}-01$ & $5.6113 \mathrm{e}-06$ & $2.5067 \mathrm{e}-05$ \\
& & & & & \\
\hline $\mathbf{2 . 0 3} * \mathbf{1 0}$ & 1.4420 & -2.5413 & $1.3623 \mathrm{e}-01$ & $1.2834 \mathrm{e}-04$ & $2.2063 \mathrm{e}-04$ \\
& & & & & \\
\hline
\end{tabular}

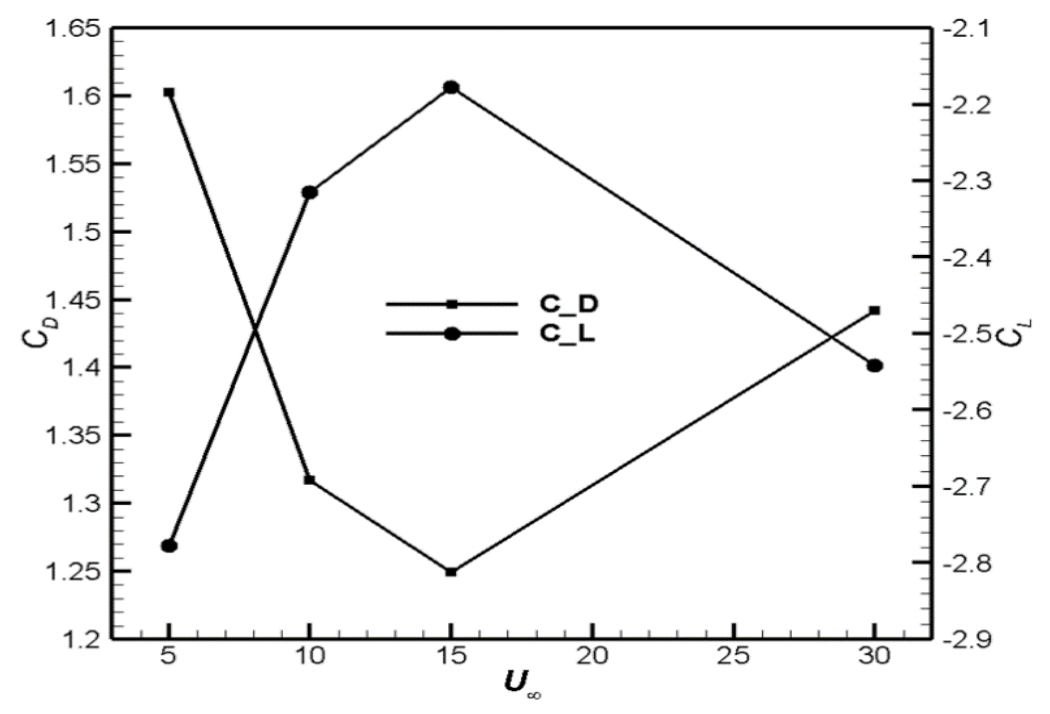

Şekil 6. Sürüklenme ve kaldırma katsayıların serbest akış hızlarına göre dağılımı.

\section{TEŞEKKÜR (ACKNOWLEDGMENTS)}

Harran CFD grubu tarafından yürütülen çalışma GAPYENEV ve Harran HPC Merkezi tarafindan desteklenmiştir. 


\section{KAYNAKLAR (REFERENCES)}

[1] A. Abiola-Ogedengbe, H. Hangan, K. Siddiqui, Experimental investigation of wind effects on a stand alone photovoltaic (PV) modüle. Renewable Energy, 78: (2015) 657-665.

[2] M. Shademan, R. M. Barron, R. Balachandar, H. Hangan, Numerical simulation of wind loading on ground-mounted solar panels at different flow configurations. Can J CivEng, 41:7 (2014) 28-38.

[3] R. Velicu, G. Moldovean, I. Scaletchi, B. R. Butuc, Wind loads on an azimuthal photovoltaic platform experimental study. In: Proceeding of International Conference on Renewable Energies and Power Quality, Granada, Spain, 2010.

[4] R. N. Meroney, D. E. Neff, Wind effects on roof mounted solar photovoltaic arrays: CFD and windtunnel evaluation. In: The Fifth International Symposium on Computational Wind Engineering, North Carolina, (2010) 23-27.

[5] C. M. Jubayer, H. Hangan, A numerical approach to the investigation of wind loading on an array of ground mounted solar photovoltaic (PV) panels. Journal of Wind Engineering and Industrial Aerodynamics, 153: (2016) 60-70.

[6] M. K. Zemler, G. Bohl, O. Rios, S. K. S. Boetcher, Numerical study of wind forces on parabolic solar collectors. Renewable Energy, 60: (2013) 498-505.

[7] K. Harstveit, Full scale measure ments of gust factors and turbulence intensity and their relations in hilly terrain. Journal of Wind Engineering and Industrial, 61: (1996) 195-205.

[8] F. Toja-Silva, C. Peralta, O. Lopez-Garcia, J. Navarro, I. Cruz, Effect of roof-mounted solar panels on the wind energy exploitation on high rise buildings. Journal of Wind Engineering and Industrial Aerodynamics, 145: (2015) 123-138.

[9] D. Banks, The role of corner vortices in dictating peak wind loads on tilted flat solar panels mounted on large, flat roofs. Journal of Wind Engineering and Industrial Aerodynamics, 123: (2013) 192-201.

[10] A. Radu, E. Axinte, C. Theohari, Steady wind pressures on solar collectors on flat roofed buildings. Journal of Wind Engineering and Industrial Aerodynamics, 23: (1986) 249-258.

[11] G. S. Wood, R. O. Denoon, K. C. Kwok, Wind loads on industrial solar panel arrays and supporting roof structure. Wind Struct, 4: 6 (2001) 481-494.

[12] S. İzol, Güneş Panelleri Üzerine Gelen Rüzgâr Yüklerinin Deneysel ve Nümerik Araştırılması, Harran Üniversitesi, Fen Bilimleri Enstitüsü, Yüksek Lisans Tezi, Şanlıurfa, 2019.

[13] Z. A. Fıratoğlu, S. İzol, Y. Işıker, Bir Fotovoltaik Panel Etrafındaki Akış Karakteristiklerinin Aerodinamik Kuvvetler Üzerine Etkisinin Araştırılması, Harran Üniversitesi Mühendislik Dergisi, 5:2 (2020) 94-108.

[14] D. C. Wilcox, Turbulence modelling for CFD. DCW Industries, 1993.

[15] A. Roulund, B. M. Sumer, J. Fredsoe, J. Michelsen, Numerical and experimental investigation of flow and scour around a circular pile, Journal of Fluid Mechanic, $53: 4$ (2005) 351-401. 